at the base of an undisturbed midden must be older than those at the top." In every ointment there is some fly.

FLORENCE M. HAWLEY

University of New Mexico

Albuquerque, New Mexico

\title{
Credit to Professor Moorehead
}

Through an oversight no reference was made, in a paper on the "The Simple Bone Point" of the Shell-Heaps of the Northeastern Algonkian Area(This series Vol. I, No. 4, 1936), to the contributions of Professor Warren K. Moorehead on the subject. In view of the extent of his archaeological explorations in Maine this was most unfortunate and the author hastens to apologize. It may be pointed out, however, that in the above paper, as the title indicates, no attempt is made to deal with the general subject of the archaeology of Maine, but the subject matter is for the most part restricted to the consideration of a single type of object.

The description of bone points of the type under discussion furnished in Professor Moorehead's report: Archaeology of Maine, Andover Press, 1922, is, to say the least, meagre. Under the title "Long Bones," there are about eight sentences having direct reference to these points in which the only descriptive terms employed are "small, pointed, polished objects." The brief discussion deals otherwise almost wholly with hypothesis. An excellent photographic plate bearing the legend: "Fig. 100. Typical arrow-points and fish hooks of which several thousand have been found,-From shell heaps. S. 1-1." serves nevertheless definitely to identify them. The selection of specimens of sharppointed, complete bone points for this illustration has failed not only to bring out a very characteristic feature, namely, the almost constantly occurring fracture and chipping, of a type that could be accomplished only by violent terminal impact, but also other characteristics such as the extent of the surface polished, bipolar and bilateral asymmetry, are not adequately shown, and orientation is neglected.

Professor Moorehead's recently expressed views in regard to the significance of the bone points in question (This series, Vol. II, No. 2, 1936) appear to lack factual support. The important and regularly occurring characteristic of dulling through successive terminal impacts is again omitted from his discussion. While we see no reason why sharpened bone points should not have been employed on the coast of Maine for fishhooks and gorges, this possibility furnishes no basis for the assumption that bone objects of a special type regularly showing fracture by terminal impact were so used. The polishing and continued use in many instances of dull and fractured points of this type, without sharpening, seems incompatible with the fishhook hypothesis. The possible usage of the simple bone point for purposes for which it was not intended 
is, of course, not denied. We have the familiar examples of the employment of stone projectile points for drills, reamers and scrapers.

The quite obvious advantages of the large or "broad-head" type of arrow point for killing large game are likewise not disputed. In fact, stone points which might serve this purpose are quite common in Maine shell-heaps and the iron "trade" points found in these sites are notably large for arrow points. On the other hand, in view of the prevalence in New England of very minute stone points, and others made as long and narrow as it was possible to make them of such material, it seems clear that points not especially well adapted for killing large game, were widely employed. I have no information as to the incidence of very small stone points in the Maine shell-heaps beyond the fact that small narrow forms have been found that would make no greater wounds than a moderate-sized bone point. Further than expressing reasons for concluding that they were projectile points, I am not aware that I have implied any specialized usage of the simple bone points.

The apparent absence of these objects in sites away from the coast in contrast with their frequency in shell-heaps, may be accounted for by the perishable nature of bone except under certain conditions, as for example those furnished in shell deposits. If numbers of bone artifacts of other types were to be found in interior sites, only then would the absence of the simple bone point be significant. It is quite possible that some future discovery may throw new light on the subject and show that simple bone points were employed for quite another purpose than for projectile points, but with the information at hand the latter hypothesis appears to furnish the most probable explanation.

\author{
ERnest E. Tyzzer \\ Harvard Medical School \\ Boston, Massachusetts
}

\title{
Southwestern Trade in Shell Products
}

In the article: $A$ Shell Bracelet Manufactory, by Arthur Woodward, which appeared in the October, 1936, issue of this journal (Vol. II, No. 2, pp. 117125), Mr. Woodward states that the origin of Glycimeris shell artifacts found over the Southwest "has not been established." Although Dr. Sauer and I did not explicitly mention (in our report of 1931) the Boquillas and other west Sonoran sites as presumptive shell gorget and bracelet manufacturing centers, and as sources for trade to the north and east, this was implicit in the printed discussion, and was certainly in our minds at the time of discovery. Furthermore, concrete expression was given to these propositions in my article: Prehistoric Trade in the Southwest. ${ }^{210}$ The following quotations from this article contain the pertinent material:

"Sea shells are the best markers of long prehistoric trade routes in the South-

${ }^{210}$ New Mexico Business Review, Vol. 4, No. 4, pp. 202-209, Oct., 1935. 